\title{
ПРОФЕССИОНАЛЬНАЯ ИДЕНТИЧНОСТЬ ЛИЧНОСТИ
}

\author{
Кучеренко Светлана Валериевна \\ кандидат психологических наук, дочент, \\ Гуманитарно-педагогическая академия (филиал) \\ ФГАОУ ВО «Крымский федеральный университет»
}

в г. Ялте

Аннотация. В статье изложены результаты качественного исследования профессиональной идентичности личности преподавателя вуза. Методами исследования являются каузометрия А.А. Кроника и цветоассоциативный эксперимент (авторская модификация ассоциативного эксперимента К.Г. Юнга). Предложена модель профессиональной идентичности, состоящая из следующих компонентов: события профессиональной жизни; самоосознавание себя как представителя профессии, профессионально значимые черты с точки зрения самого субъекта. Данная модель требует дальнейшей эмпирической проверки.

Summary. The article presents the results of a qualitative research of the professional individual identity as a component of self-consciousness. The research methods are A. A. Kronik's causometry and color-associative experiment (the author's modification of K. G. Jung's associative experiment). A model of professional identity is proposed, consisting of the following components: events of professional life; self-awareness of oneself as a representative of the profession, professionally significant features from the point of view of the subject himself. This model requires further empirical testing.

Ключевые слова: профессиональная идентичность, самосознание, самоосознавание, каузометрия, цветоассоциативный эксперимент, поток ассоциаций.

Key words: professional identity, self-awareness, self-consciousness, causometry, color-associative experiment, the flow of associations.

На сегодняшний день в психологической литературе профессиональная идентичность личности изучена недостаточно. Профессиональная идентичность как форма проявления социальной идентичности рассматривается рядоположено с понятиями «профессиональная Я-концепция» и «профессиональное Я». Разграничение вышеперечисленных понятий необходимо для построения дальнейшего эмпирического изучения профессиональной идентичности студентов в процессе дистанционного обучения.

Объект исследования: профессиональная идентичность как психолого-педагогическая проблема подготовки студентов-психологов в вузе.

Предмет исследования: становление профессиональной идентичности в процессе профессионального дистанционного образования.

Наиболее разработанной концепцией идентичности является концепция Э. Эриксона [10]. По Эриксону, идентичность - это чувство самотождественности, собственной истинности, сопричастности миру и другим людям. Среди отечественных психологов, затрагивающих вопросы идентичности, является И.С. Кон [4]. Он определяет идентичность как осознанную принадлежность к определенной категории людей. Таким образом, это структура сознания, а именно, самосознания.

А. Ватерман, О.Н. Дериси [8] считают, что идентичность связана с наличием у человека четкого самоопределения, включающего в себя выбор целей, ценностей и убеждений, которым человек следует в своей жизни. Поскольку цели, ценности и убеждения А. Ватерман называет элементами идентичности, то элементами профессиональной идентичности можно считать профессиональные цели, ценности и убеждения. Ценности, в том числе касающиеся профессиональной жизни, исследованы мною ранее [6] и предложена схема построения типологии личности на основе особенностей строения ценностно-смысловой сферы. Для их исследования можно применить проблемное интервью, контент- и нарративный анализ, свободный и направленный цветоассоциативный эксперимент.

А. Ватерман рассматривает идентичность во взаимосвязи процессуальной и содержательной сторон. Вопервых, процесс формирования и существования идентичности охватывает средства, с помощью которых человек идентифицирует, оценивает и отбирает ценности, цели и убеждения, которые впоследствии станут элементами его идентичности. Во-вторых, идентичность невозможно рассматривать без учета содержательной специфики целей, ценностей и убеждений, которые человек выбирает.

Синергетический подход к изучению идентичности личности обусловливает разработку проблем идентичности в более широком контексте: от социокультурных установок до теоретико-познавательных предпочтений и поиска смысла в языке и с помощью языка. Сознание как процесс и результат осознания, в том числе и самоосознавания, можно представить в виде замкнутого контура с “Я-образом", через который периодично пробегает импульс “чистого” Я: момент пересечения импульсом точки замыкания есть момент 
осознанного «схватывания» себя и мира, т. е. идентичности. Можно сказать, что в такой модели сознание имеет пульсирующую, виртуальную природу.

При этом динамика идентичности заключается в новой самореференции, которая может отличаться от прежней, т. е. происходит изменение личности.

Таким образом, идентичность - многомерный процесс человеческого становления, который может быть описан с помощью моментального осознания себя в мире, описываемый категориями свободы, ответственности, выбора, самоопределения, самоорганизации, персонализации. Л.Б. Шнейдер [8] связывает понятие профессиональной идентичности и профессионального самоопределения. Порождающими механизмами профессиональной идентичности является процесс профессиональной идентификации и профессионального отчуждения. Реализующими механизмами выступают: профессиональная ситуация, профессиональные отношения и образ «профессионального Я». Описательный механизм профессиональной идентичности включает в себя когнитивную, эмоциональную и поведенческую составляющие.

В контексте системной антропологической психологии «идентичность - это не то, что можно получить единожды в акте идентификации, а потом многократно пользоваться» результатом этого акта как некоторым завершенным продуктом, готовым к использованию в качестве оценочной базы. Однако это и не то, что необходимо постоянно восстанавливать, воспроизводить заново, одним словом, переосуществлять. «Становление - это прогрессивное усложнение открытых систем и одновременно способ их существования» [3, С. 335]. Другими словами, профессиональная идентичность - психическое явление, существующее в процессе бесконечного профессионального становления. То есть, профессиональную идентичность невозможно формировать или развивать, она находится в процессе постоянного становления. Другими словами, это интегральная оценка состояния процесса саморазвития. Таким образом, профессиональная идентичность - это интегральная оценка личностью собственного процесса профессионального саморазвития.

Идентичность зависит от того, насколько успешно (т.е. своевременно) осуществляется переход возможности в действительность и действительности в желаемое, или хотя бы приемлемое, бытие [3, С. 336]. То есть, насколько успешно возможности личности реализуются в профессиональной деятельности и насколько профессиональные ожидания оправдываются. То есть, профессиональная идентичность складывается благодаря тому, что личность реализует собственные возможности в данной профессии в конкретных условиях. Этот аспект ситуативен и зависит от условий жизни и социокультурной среды, в которой личность проявляет, ищет и находит свое место. Для эмпирической диагностики данного проявления профессиональной идентичности целесообразно применить событийный подход А.А. Кроника и метод каузометрии [5].

Таким образом, профессиональная идентичность, это не структура личности или качество, обеспечивающее человеку тождественность самому себе, но сам процесс профессионального саморазвития, дающий устойчивость, которую человеку необходимо открыть, освоить и принять. К сущностным чертам профессиональной идентичности относят: 1) ее источником выступает определенный культурно-социальный контекст, 2) она складывается в процессе осуществления череды событий профессиональной жизни, 3) проявляется в определенных актах самоосознавания или сфокусированности на профессиональной деятельности и 4) содержит в себе определенное представление о перечне профессионально значимых черт и качеств (профессиональная «Я-концепция»). Таким образом, получаем следующую модель профессиональной идентичности (рис. 1).

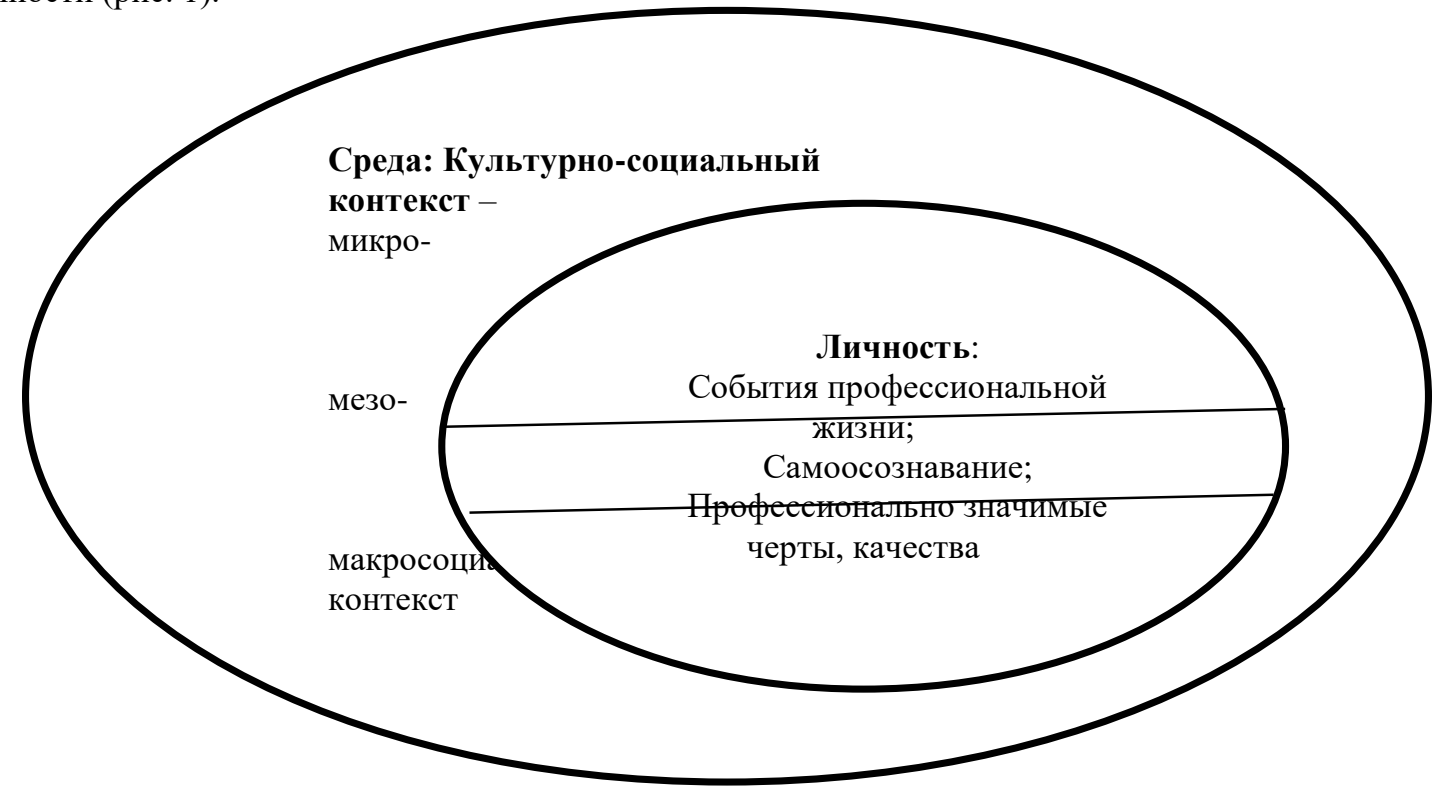


Как видно из рисунка 1, структурные компоненты профессиональной идентичности (события профессиональной жизни; самоосознавание и самопрезентация; профессионально значимые черты с точки зрения самого субъекта) осуществляются и реализуются на трех уровнях - микро-, мезо-, и макросоциальном. Важно также, что каждый из этих структурных компонентов можно диагностировать эмпирически: с помощью событийного анализа (каузометрии) А.А. Кроника [5] или профессионального самоописания [8], самоосознавание - методикой «кто Я?» М. Куна, Т. Макпартленда или авторской модификацией ассоциативного эксперимента К.Г. Юнга - цветоассоциативным экспериментом [12], профессионально значимые черты и качества - также цветоассоциативным экспериментом [12].

Если рассматривать события жизни в общем и целом, а не только происходящие в профессиональной жизни, то целесообразно использовать метод анализа значимых событий А.А. Кроника или метод каузометрии $[1 ; 5]$, см. табл. 1-3. Рассмотрим пример такого анализа. Респондентом выступает преподаватель кафедры психологии Гуманитарно-педагогической академии (филиала) Крымского федерального университета им. В.И. Вернадского в г. Ялте.

Таблица 1

\section{Содержательные характеристики событий жизни респондента}

\begin{tabular}{|c|c|c|c|c|c|}
\hline \multirow{2}{*}{$\begin{array}{l}\text { № } \\
\Pi / \Pi\end{array}$} & \multirow{2}{*}{ Название событий } & \multirow{2}{*}{ Возраст (лет) } & \multirow{2}{*}{ Дата } & \multicolumn{2}{|c|}{ Сферы } \\
\hline & & & & Главная & Другие \\
\hline 1 & Рождение & $\mathrm{X}$ & $\mathrm{X}$ & $\mathrm{C}^{*}$ & $\Pi^{*}$ \\
\hline 2 & Поступление в худож.шк. & $\mathrm{X}$ & $\bar{X}$ & $\mathrm{P}$ & Д \\
\hline 3 & Поступление в колледж, университет & $\mathrm{X}$ & $\mathrm{X}$ & $\mathrm{P}$ & $\mathrm{O}$ \\
\hline 4 & Защита диссертации & $\mathrm{X}$ & $\mathrm{X}$ & $\mathrm{P}$ & $\mathrm{O}$ \\
\hline 5 & Свадьба & $\bar{X}$ & $\bar{X}$ & $\mathrm{C}$ & \\
\hline 6 & Рождение сына & $\mathrm{X}$ & $\bar{X}$ & $\mathrm{C}$ & $\Pi$ \\
\hline 7 & «Крымская весна» & $\mathrm{X}$ & $\mathrm{X}$ & $\mathrm{O}$ & $\mathrm{P}$ \\
\hline 8 & Рождение дочери & $\mathrm{X}$ & $\mathrm{X}$ & $\mathrm{C}$ & $\Pi$ \\
\hline 9 & Переезд на съемную квартиру & $\mathrm{X}$ & $\bar{X}$ & $\mathrm{C}$ & \\
\hline 10 & Выход на работу в ун-т. & $\mathrm{X}$ & $\mathrm{X}$ & $\mathrm{P}$ & $\mathrm{O}$ \\
\hline 11 & Покупка собственного жилья & $\mathrm{X}$ & $\mathrm{X}$ & $\mathrm{C}$ & $\Pi$ \\
\hline 12 & Поступление сына в школу & $\mathrm{X}$ & $\mathrm{X}$ & $\mathrm{P}$ & $\mathrm{C}$ \\
\hline 13 & Публикация книги, монографии & $\mathrm{X}$ & $\mathrm{X}$ & $\mathrm{P}$ & $\mathrm{O}$ \\
\hline 14 & $\begin{array}{c}\text { Окончание детьми школы, поступление в } \\
\text { вуз }\end{array}$ & $\mathrm{X}$ & $\mathrm{X}$ & $\mathrm{P}$ & $\mathrm{C}$ \\
\hline 15 & Свадьба сына, дочери & $?$ & $?$ & $\mathrm{C}$ & Д \\
\hline 16 & Рождение внуков & $?$ & $?$ & $\mathrm{C}$ & $\Pi$ \\
\hline 17 & Путешествия по миру & $?$ & $?$ & Д & $\mathrm{O}, \Pi$ \\
\hline 18 & Персональная выставка & $?$ & $?$ & Д & $\mathrm{P}, \mathrm{O}$ \\
\hline & Всего: & & & C-8, P-7, Д-2, О-1 & $\begin{array}{c}\text { C-2, } \mathbf{\Pi - 5}, \mathrm{o}-6, \mathrm{p}-2, \text { д- } \\
2\end{array}$ \\
\hline
\end{tabular}

* - С - семья, П - природа, Р - работа, Д - друзья, О - общество.

Таблица 2

Протокол каузометрического опроса респондента

\begin{tabular}{|c|c|c|c|c|c|c|c|c|c|c|c|c|c|c|c|c|c|c|}
\hline \multirow{13}{*}{ 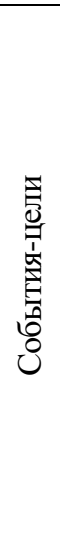 } & & \multicolumn{15}{|c|}{ События-следствия } & & 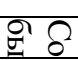 \\
\hline & & 1 & 2 & 3 & 4 & 5 & 6 & 7 & 8 & 9 & 10 & 11 & 12 & 13 & 14 & 15 & & \\
\hline & 1 & 69 & +++ & +++ & +++ & +++ & +++ & --- & +++ & +++ & +++ & +++ & +++ & +++ & +++ & +++ & 1 & \\
\hline & 2 & +++ & 44 & ++ & +++ & ++ & + & --- & ++ & ++ & + & + & ++ & ++ & ++ & - & 2 & \\
\hline & 3 & + & + & 60 & +++ & ++ & ++ & --- & ++ & + & +++ & + & ++ & +++ & ++ & - & 3 & \\
\hline & 4 & + & ++ & +++ & 63 & +++ & ++ & --- & ++ & + & +++ & ++ & ++ & +++ & + & --- & 4 & \\
\hline & 5 & +++ & ++ & ++ & +++ & 69 & +++ & --- & +++ & +++ & + & +++ & +++ & -- & +++ & +++ & 5 & \\
\hline & 6 & +++ & + & ++ & ++ & +++ & 63 & --- & +++ & ++ & +++ & ++ & +++ & -- & +++ & +++ & 6 & \\
\hline & 7 & - & 0 & -- & 0 & 0 & 0 & 61 & +++ & +++ & ++ & ++ & ---- & --- & --- & --- & 7 & \\
\hline & 8 & +++ & + & ++ & ++ & +++ & +++ & + & 70 & +++ & +++ & +++ & +++ & --- & +++ & +++ & 8 & \\
\hline & 9 & ++ & ++ & +++ & + & +++ & ++ & ++ & ++ & 61 & ++ & +++ & ++ & +++ & + & + & 9 & \\
\hline & 10 & ++ & + & +++ & +++ & ++ & ++ & +++ & ++ & +++ & 67 & +++ & ++ & +++ & +++ & + & 10 & \\
\hline & 11 & ++ & + & +++ & +++ & +++ & +++ & +++ & +++ & +++ & +++ & 69 & +++ & +++ & ++ & +++ & 11 & \\
\hline
\end{tabular}




\begin{tabular}{|c|c|c|c|c|c|c|c|c|c|c|c|c|c|c|c|c|}
\hline 12 & +++ & ++ & ++ & +++ & +++ & +++ & +++ & +++ & ++ & +++ & ++ & 70 & + & +++ & ++ & 12 \\
\hline 13 & +++ & ++ & +++ & +++ & + & --- & --- & --- & +++ & +++ & +++ & ++ & 68 & ++ & - & 13 \\
\hline 14 & ++ & + & ++ & ++ & ++ & +++ & ++ & ++ & ++ & +++ & ++ & +++ & + & 62 & + & 14 \\
\hline 15 & + & + & + & + & ++ & + & + & + & + & + & + & ++ & + & +++ & 47 & 15 \\
\hline & 1 & 2 & 3 & 4 & 5 & 6 & 7 & 8 & 9 & 10 & 11 & 12 & 13 & 14 & 15 & \\
\hline
\end{tabular}

Мотивационный статус событий жизни (\%)

\begin{tabular}{|c|c|c|c|c|c|c|c|c|c|c|c|c|c|c|c|}
\hline № & 1 & 2 & 3 & 4 & 5 & 6 & 7 & 8 & 9 & 10 & 11 & 12 & 13 & 14 & 15 \\
\hline $\begin{array}{c}\text { абс. } \\
\text { знач. }\end{array}$ & 82,14 & 52,38 & 71,43 & 75 & 82,14 & 75 & 72,62 & 83,33 & 72,62 & 79,76 & 82,14 & 83,33 & 80,95 & 73,81 & 55,95 \\
\hline ранг & 3 & 15 & 13 & 8 & 4 & 9 & 11 & 1 & 12 & 7 & 5 & 2 & 6 & 10 & 14 \\
\hline $\begin{array}{c}\text { абс. } \\
\text { знач. }\end{array}$ & 80,95 & 51,19 & 64,29 & 67,86 & 76,19 & 69,05 & 29,76 & 76,19 & 72,62 & 79,76 & 82,14 & 79,76 & 57,14 & 70,24 & 45,24 \\
\hline ранг & 2 & 13 & 11 & 10 & 5 & 9 & 15 & 5 & 7 & 3 & 1 & 3 & 12 & 8 & 14 \\
\hline
\end{tabular}

Для вычисления показателей насыщенности прошлого ( $\mathrm{R}$ - реализованность), настоящего (А - актуальность) и будущего (P - потенциальность) в каузоматрице между двумя событиями, которые отделяют хронологическое прошлое от хронологического будущего, по вертикали и горизонтали проводят разделительную линию (Табл. 2). Если в картине жизни имеются связи между событиями и прошлого, и будущего, то после разделения каузоматрицы по линии хронологического настоящего в верхнем левом углу матрицы будут реализованные связи, в нижнем правом углу - потенциальные связи, в верхнем правом и нижнем левом углах матрицы расположатся актуальные связи. Количество реализованных, актуальных и потенциальных связей приведено в табл. 4. Подсчет психологического возраста и мотивационной насыщенности жизни в прошлом, настоящем и будущем приведен в табл. 5.

Таблица 4

Количество связей в каузоматрице

\begin{tabular}{|c|c|c|c|c|}
\hline \multirow{2}{*}{ Связи } & \multicolumn{4}{|c|}{ Количество связей } \\
\cline { 2 - 5 } & Реализованные & Актуальные & Потенциальные & Всего \\
\hline Причинные & 109 & 121 & 21 & 251 \\
\hline Целевые & 74 & 113 & 20 & 207 \\
\hline Всего & 183 & 234 & 41 & 458 \\
\hline
\end{tabular}

$\mathrm{R}=183 / 458 \times 100=39,96 \%$ (коэф. Реализованности, прошлое)

$\mathrm{A}=234 / 458 \times 100=51,09 \%$ (коэф. Актуальности, настоящее)

$\mathrm{P}=41 / 458 \times 100=8,95 \%$ (коэф. Потенциальности, ожидаемое будущее)

Таблица 5

Психовозрастные показатели респондента

\begin{tabular}{|c|c|c|c|c|}
\hline Психовозрастные показатели & Прошлое (R) & Настоящее (А) & Будущее (Р) & В целом \\
\hline Мотивационная насыщенность & $39,96 \%$ & $51,09 \%$ & $8,95 \%$ & $33,33 \%$ \\
\hline Психологический возраст* & 31,97 лет & & & ОПЖ $=80$ \\
\hline Коэффициент Взрослости** & $88,8 \%$ & & & \\
\hline
\end{tabular}

$* \Pi \mathrm{B}=\mathrm{R} \times \mathrm{O} \Pi / 100=31,97 . * * \mathrm{~KB}=(\Pi \mathrm{\Pi} / \mathrm{XB}) \times 100=88,8 \%$

Таким образом, каузометрия показала, что одним из наиболее значимых событий жизни респондента является профессиональным (ранг 3, № 10 - выход на работу в университет), что свидетельствует о важности профессиональной реализации и сформированности профессиональной идентичности как момента осознанного схватывания себя в определенной профессии. В акте самоосознавания данного респондента присутствует профессиональная отнесенность, причем большинство профессиональных событий находятся в прошлом и настоящем, что может свидетельствовать о профессиональном кризисе личности.

Рассмотрим содержание профессиональной идентичности респондента. Для этого проанализируем поток ассоциаций данного респондента на стимул «профессиональная жизнь». Слова и словосочетания: «1. Психология 2 X. 2. Арт-терапия 4 +. 3. Помощь $3=$. 4. Сопровождение 0 -. 5. Присутствие в моменте $3=.6$. Понимание $1=.7$. Причастность 5 X. $8 . \quad$ Прикосновение к внутреннему миру $1=.9$. Диалог 4 +. 10.

Субъект 2 Х. 11. Человек 4 +. 12. Клиент 4 +. 13. Группа 0 -. 14. Студенты 2 Х. 15. Кафедра 5 X. 16.

Администрация 6 -. $17 . \quad$ Нормы рабочего времени 0 -. 18. Научные статьи 2 Х. 19. Конференции 4 +. 20. Публикации 2 Х. 21. Монография 5 Х. 22. Сборник статей $1=$. 23. Возможности реализации 
4 +. 24. Принятие ограничений $3=.25$. Поиск 4 +. 26. Научные исследования 2 Х. 27. Книги 4 +. 28. ЭОР $1=.29$. Сеть интернет 0 -. 30. Библиографическое описание $1=.31$. Выводы 2 Х. 32. Интерпретация 5 Х. 33. Диагностические методики $3=.34$. Рабочая неделя 0 -. 35. Лекции $3=.36$. Практические занятия $4+.37$. Детский аутизм 0 -. 38. Имидж $1=.39$. Профессиональная этика 7 -. 40. Дисциплина 7 -. 41.

Самоорганизация 2 X. 42. Цоколь 0 -. 43. Свежий воздух $4+.44$. Солнечный свет $3=.45$. Журнал учета работы академической группы 6 -. 46. Проблемная группа 5 X. 47. Коллеги 1. 48. Конференции 5 Х. 49. Проекты 5 X. 50. Познавательная активность $4+$ +. 51. Мотивация 2 Х. 52. Эффективный контракт $1=.53$. Отчет 0 -. 54. Аванс $1=.55$. Отпуск $4+.56$. Конкурс на замещение вакантной должности $3=»$.

Процессуальная сторона характеризует порядок слов, их последовательность, в то время как смысл слов содержательную сторону профессиональной идентичности. В этом потоке выделяем слова, которые можно отнести к категориям «цель», «ценность», «убеждение» (см. Табл. 6).

Таблица 6.

Категориальный анализ потока ассоциаций респондента на стимул «профессиональная жизнь»

\begin{tabular}{|c|c|c|}
\hline Слова, обозначающие цели & $\begin{array}{c}\text { Слова, обозначающие ценности (средства } \\
\text { достижения цели) }\end{array}$ & $\begin{array}{c}\text { Слова, обозначающие убеждения } \\
\text { относительно стимула }\end{array}$ \\
\hline Помощь 3 =* & $\begin{array}{c}\text { Психология } 2 \mathrm{X} \\
\text { Арт-терапия 4+ } \\
\end{array}$ & (Нужно) Присутствие в моменте 3 = \\
\hline $\begin{array}{c}\text { Прикосновение к } \\
\text { внутреннему миру } 1=\end{array}$ & $\begin{array}{c}\text { Понимание } 1= \\
\text { Причастность } 5 \text { X }\end{array}$ & $\begin{array}{c}\text { (все друг другу должны быть) } \\
\text { Субъект(ы) } 2 \text { X }\end{array}$ \\
\hline Диалог 4 + & $\begin{array}{c}\text { Человек 4+ } \\
\text { Клиент } 4+ \\
\text { Группа } 0 \text { - } \\
\text { Студенты } 2 \text { X } \\
\text { Кафедра } 5 \text { X } \\
\end{array}$ & $\begin{array}{c}\text { (уважать) Администрация } 6 \text { - } \\
\text { (существуют) Нормы рабочего времени } \\
0 \text { - }\end{array}$ \\
\hline Возможности реализации $4+$ & $\begin{array}{l}\text { Научные статьи } 2 \text { X } \\
\text { Конференции } 4+ \\
\text { Публикации } 2 \text { X } \\
\text { Монография } 5 \text { X } \\
\text { Сборник статей } 1= \\
\end{array}$ & (Нужно) Принятие ограничений $3=$ \\
\hline Поиск $4+$ & $\begin{array}{c}\text { Научные исследования } 2 \text { X } \\
\text { Книги } 4+ \\
\text { ЭОР } 1 \text { = Библиографическое описание } 1=\end{array}$ & $\begin{array}{c}\text { (все есть в) Сеть интернет 0- } \\
\text { (должны быть) Выводы } 2 \text { X } \\
\text { (важна) Интерпретация } 5 \text { X } \\
\text { Диагностические методики (должны } \\
\text { быть релевантны) } 3=\end{array}$ \\
\hline Свежий воздух $4+$ & $\begin{array}{c}\text { Имидж } 1 \text { = } \\
\text { Профессиональная этика } 7 \text { - } \\
\text { Дисциплина } 7 \text { - } \\
\text { Самоорганизация } 2 \text { X }\end{array}$ & $\begin{array}{c}\text { (Нужно) Рабочая неделя } 0 \text { - } \\
\text { (должна) Лекции } 3= \\
\text { (должна проводить) Практические } \\
\text { занятия } 4+ \\
\text { (должно) Детский аутизм } 0 \text { - }\end{array}$ \\
\hline $\begin{array}{c}\text { Проекты } 5 \text { X } \\
\text { Познавательная активность } 4 \\
+ \\
\text { Мотивация } 2 \mathrm{X}\end{array}$ & $\begin{array}{c}\text { Журнал учета работы академической } \\
\text { группы } 6 \text { - } \\
\text { Проблемная группа } 5 \text { X } \\
\text { Коллеги } 1 \\
\text { Конференции } 5 \text { X }\end{array}$ & $\begin{array}{c}\text { (Нужно) Солнечный свет } 3= \\
\text { (должна работать в) Цоколь } 0- \\
\text { (должна) Эффективный контракт } 1= \\
\text { (должна) Отчет } 0 \text { - } \\
\text { (Нужно) Аванс } 1= \\
\text { (Нужно) Отпуск } 4+ \\
\text { (должна) Конкурс на замещение } \\
\text { вакантной должности } 3= \\
\end{array}$ \\
\hline 9 единиц & 26 единиц & 20 единиц \\
\hline
\end{tabular}

* - обозначение эмоционального отношения к слову или словосочетанию на основании ранжирования цветов восьмицветового субтеста М. Люшера и ассоциирования каждого слова или словосочетания с одним из цветов в соответствии с алгоритмом проведения цветоассоциативного эксперимента [14]: «+» означает положительное отношение, «Х» означает положительное отношение, но менее выраженное, «=» означает индифферентность, «» негативное отношение, избегание данного явления.

Как видно из таблицы 6, большинство целей вызывают положительное эмоциональное отношение, кроме двух индифферентных - «помощь» и «прикосновение к внутреннему миру» другого человека. Важно также, что в категорию профессиональных целей попали также слова и словосочетания, характеризующие функцию 
личности как представителя профессии психолога («помощь» и «прикосновение к внутреннему миру»), условия («свежий воздух») и результаты профессиональной деятельности («проекты», «познавательная активность» и «мотивация»). Больше всего в потоке ассоциаций слов, обозначающих ценности (26 единиц), которые вполне соответствуют целям-функциям, целям-условиям и целям-результатам профессиональной деятельности с точки зрения данного респондента. Среди убеждений в профессиональной идентичности выделяются такие смысловые единицы: потребности «надо», «важно» и «должно», причем утверждения-долженствования лидируют (10 единиц).

Таким образом, в индивидуальном семантическом пространстве профессиональной идентичности респондента присутствуют категории собственно профессиональных целей («диалог», «возможности реализации» и «поиск»), целей-профессиональных функций («помощь» и «прикосновение к внутреннему миру»), целей-условий («свежий воздух») и целей-результатов («проекты», «познавательная активность» и «мотивация»). Описанная индивидуальная картина профессиональных целей, ценностей и убеждений дает нам возможность охватить актуальную профессиональную идентичность респондента.

Выводы. Совместив результаты каузометрии А.А. Кроника и цветоассоциативного эксперимента (авторской психосемантической методики на основе ассоциативного эксперимента К.Г. Юнга), исследователь получает срез актуальной профессиональной идентичности респондента, причем не мнимой или декларируемой, а действительно переживаемой и установленной на момент диагностики, что соответствует синергетическому, а именно, транстемпоральному подходу О.В. Лукьянова в изучении идентичности личности.

Описанная модель профессиональной идентичности личности включает в себя профессиональные события личности, акты осознавания себя в соотнесенности с целями, ценностями и убеждениями определенной профессиональной группы, в том числе, профессионально значимые качества личности. Описанная теоретическая модель ожидает дальнейшей эмпирической проверки в различных микро-, мезо- и мегасоциокультурных срезах профессиональной идентичности личности.

\section{Литература:}

1. Ахмеров, Р.А. Событие как элемент субъективной картины жизненного пути / Рашад Анварович Ахмеров // Современные исследования социальных проблем (электронный научный журнал), Modern Research of Social Problems. - 2013. - №10 (30). - 19 с. - DOI: 10.12731/2218-7405-2013-10-34. - Режим доступа: https://cyberleninka.ru/article/n/sobytie-kak-element-subektivnoy-kartiny-zhiznennogo-puti

(дата обращения 18.07.2018).

2. Ганзен В.А. Системные описания в психологии / Ганзен В.А. - Л.: Изд-во Ленингр. ун-та, 1984. $-176 \mathrm{c}$.

3. Клочко В.Е. Личностная идентичность и проблема устойчивости человека в меняющемся мире: системноантропологический ракурс / В.Е. Клочко, О.В. Лукьянов // Вестник Томского государственного университета. 2009. - № 324. - С. 333-336.

4. Кон, И.С. В поисках себя / И.С. Кон. - М.: Политиздат, 1984. - 335 с.

5. Кроник А.А. Каузометрия: Методы самопознания, психодиагностики и психотерапии в психологии жизненного пути / А.А. Кроник, Р.А. Ахмеров. - М.: Смысл, 2003. - 284 с.

6. Кучеренко С.В. Особенности ценностно-смысловой сферы студентов: типология личности / С.В. Кучеренко // Проблемы современного педагогического образования: сборник научных трудов. Серия: Педагогика и психология. - Ялта. - 2018. - № 58 (1). - С. 331-335. - DOI: 10.24412/FemKesn51CU.

7. Лукьянов О.В. Проблема становления идентичности в эпоху социальных изменений / Олег Валерьевич Лукьянов. - Томск: Изд-во Том. ун-та, 2008. - 212 с.

8. Шнейдер, Л.Б. Профессиональная идентичность: Монография / Л.Б. Шнейдер. - М: МОСУ, 2001. - 272 с.

9. Cheek, Jonathan \& Briggs, Stephen. (1982). Self-consciousness and aspects of identity. Journal of Research in Personality. - № 16. - Pp. 401-408. DOI: 10.1016/0092-6566(82)90001-0.

10. Erikson, E. H. The concept of ego identity // Amer. Psychoanal. Assn. - 1956. - №4. - p. 56-121.

11. Juan Jos $\Gamma$ C Zacar $\Gamma$ Cs, Alejandro Iborra, Self and Identity Development during Adolescence across Cultures, Editor(s): James D. Wright, International Encyclopedia of the Social \& Behavioral Sciences (Second Edition), Elsevier, 2015, Pages 432-438, ISBN 9780080970875, https://doi.org/10.1016/B978-0-08-097086-8.23028-6.

12. Kucherenko S. Implementation of the psychosemantic method "Color-associative experiment" in psychological counseling of students / S. Kucherenko, T. Pavliuk // SHS Web of Conferences. - 2020. - 87, 00104. https://doi.org/10.1051/shsconf/20208700104 